\title{
Preliminary nonclinical safety and immunogenicity of an rVSV- $\Delta$ G-SARS-CoV-2-S vaccine in mice, hamsters, rabbits and pigs
}

\author{
Noa Madar-Balakirski ${ }^{1} \cdot$ Amir Rosner $^{2} \cdot$ Sharon Melamed $^{3} \cdot$ Boaz Politi $^{3} \cdot$ Michal Steiner $^{4} \cdot$ Hadas Tamir $^{3}$. \\ Yfat Yahalom-Ronen ${ }^{3}$. Elad Bar-David ${ }^{3} \cdot$ Amir Ben-Shmuel $^{3} \cdot$ Assa Sittner $^{3} \cdot$ Itai Glinert $^{3}$ - Shay Weiss ${ }^{3}$. \\ Erez Bar-Haim ${ }^{5} \cdot$ Hila Cohen $^{5}$. Uri Elia ${ }^{5} \cdot$ Hagit Achdout $^{3} \cdot$ Noam Erez $^{3} \cdot$ Shahar Rotem $^{5} \cdot$ Shlomi Lazar $^{1}$. \\ Abraham Nyska $^{6} \cdot$ Shmuel Yitzhaki $^{7} \cdot$ Adi Beth-Din $^{5} \cdot$ Haim Levy $^{3} \cdot$ Nir Paran $^{3} \cdot$ Tomer Israely $^{3} \cdot$ Hadar Marcus $^{8}(0)$
}

Received: 4 October 2021 / Accepted: 21 December 2021 / Published online: 15 January 2022

(c) The Author(s), under exclusive licence to Springer-Verlag GmbH Germany, part of Springer Nature 2022

\begin{abstract}
rVSV- $\Delta$ G-SARS-CoV-2-S is a clinical stage (Phase 2) replication competent recombinant vaccine against SARS-CoV-2. To evaluate the safety profile of the vaccine, a series of non-clinical safety, immunogenicity and efficacy studies were conducted in four animal species, using multiple doses (up to $10^{8}$ Plaque Forming Units/animal) and dosing regimens. There were no treatment-related mortalities or any noticeable clinical signs in any of the studies. Compared to unvaccinated controls, hematology and biochemistry parameters were unremarkable and no adverse histopathological findings. There was no detectable viral shedding in urine, nor viral RNA detected in whole blood or serum samples seven days post vaccination. The rVSV$\Delta$ G-SARS-CoV-2-S vaccination gave rise to neutralizing antibodies, cellular immune responses, and increased lymphocytic cellularity in the spleen germinal centers and regional lymph nodes. No evidence for neurovirulence was found in C57BL/6 immune competent mice or in highly sensitive type I interferon knock-out mice. Vaccine virus replication and distribution in K18-human Angiotensin-converting enzyme 2-transgenic mice showed a gradual clearance from the vaccination site with no vaccine virus recovered from the lungs. The nonclinical data suggest that the rVSV- $\Delta$ G-SARS-CoV-2-S vaccine is safe and immunogenic. These results supported the initiation of clinical trials, currently in Phase 2.
\end{abstract}

Keywords Safety $\cdot$ Nonclinical $\cdot$ Vaccine $\cdot$ COVID-19 $\cdot$ Neutralizing antibodies

\section{Introduction}

Severe acute respiratory syndrome coronavirus 2 (SARSCoV-2), a member of the Coronaviridae family, is responsible for the COVID-19 pandemic that emerged from the Wuhan Province in China in 2019 and rapidly spread

Noa Madar-Balakirski and Amir Rosner have contributed equally to this work.

Tomer Israely

tomeri@iibr.gov.il

Hadar Marcus

hadarm@iibr.gov.il

1 Department of Pharmacology, Israel Institute for Biological Research, Ness Ziona, Israel

2 Veterinary Center for Preclinical Research, Israel Institute for Biological Research, Ness Ziona, Israel

3 Department of Infectious Diseases, Israel Institute for Biological Research, Ness Ziona, Israel
4 Gsap, Matam Building 22, Haifa, Israel

Department of Biochemistry and Molecular Genetics, Israel Institute for Biological Research, Ness Ziona, Israel

6 Sackler School of Medicine, Tel Aviv University, and Consultant in Toxicologic Pathology, Tel Aviv, Israel

7 Israel Institute for Biological Research, Ness Ziona, Israel

8 Department of Biotechnology, Israel Institute for Biological Research, Ness Ziona, Israel 
globally, with over 256 million confirmed cases of COVID19 , including over 5 million deaths, reported to WHO as of 21 November 2021 , and a total of $7.4 \times 10^{9}$ vaccine doses have been administered.

Global efforts to prevent, treat and control the COVID-19 pandemic, include multiple approaches: vaccines and drug development; drug repurposing; development or isolation of neutralizing antibodies for prevention and treatment, as well as, additional therapeutic measures, such as immune modifiers and other drugs, to circumvent the overt host immune response and lung-tissue injury (Rodriguez-Guerra et al. 2021; Welte et al. 2021). Whereas vaccines are mainly intended for prevention of disease, drugs and other therapeutic countermeasures are mainly applied for the treatment of the disease. Consequently, preclinical and clinical approval of vaccines differs from that of antiviral drugs, as vaccines are intended for a large and healthy population.

The urgent need for an efficacious vaccine for SARS$\mathrm{CoV}-2$ led to unprecedented innovation worldwide. Thirteen vaccines have been approved under emergency use authorizations (EUA) in different countries (WHO Coronavirus Dashboard. Available on line https://covid19.who. int/2. In August 23, 2021, the U.S. Food and Drug Administration has approved the Biologics License Application (BLA) for Pfizer-BioNTech's vaccine COMIRNATY ${ }^{\circledR}$ to prevent COVID-19 in individuals 16 years of age and older. COMIRNATY was also the first COVID-19 vaccine to receive a conditional marketing authorization in the EU on 21 December 2020 (https://www.ema.europa.eu/en/medic ines/human/EPAR/comirnaty\#authorisation-details-secti on), and was later approved for use for children 12 years and older (14 October 2021, CHMP Product. Available on line https://www.ema.europa.eu/en/documents/product-infor mation/comirnaty-epar-product-information_en.pdf). FDA granted EUA for an additional two COVID-19 vaccines; Moderna's vaccine (December 18, 2020) and Janssen's vaccine (February 27, 2021); Astra Zeneca received conditional marketing approval for its vaccine throughout the European Union (January 29, 2021).

However, while several countries, including Israel, the United Kingdom and Canada, have made significant progress toward vaccinating a large portion of their citizens, with over $70 \%$ of their population receiving at least one vaccine dose (Our World in Data. Available on line https:// ourworldindata.org/covid-vaccinations), vaccines are not yet readily available in most countries. It is, therefore, essential to develop and produce vaccines, to promptly meet this pressing. As of 21 October 2021, more than 300 vaccines were in development using a variety of technologies, including 128 vaccines that are currently undergoing clinical trials (WHO COVID-19 vaccine tracker and landscape. Available on line https://www.who.int/publications/m/item/draft-lands cape-of-covid-19-candidate-vaccines).
We are developing rVSV- $\Delta$ G-SARS-CoV-2-S vaccine, currently in phase 2 clinical trials in Israel. rVSV- $\Delta \mathrm{G}$ SARS-CoV-2-S is a vector-based vaccine that utilizes the recombinant vesicular stomatitis virus (VSV) platform. The glycoprotein gene of VSV (VSV-G) was genetically replaced by the human codon-optimized spike protein gene of SARSCoV-2 (Lawson et al. 1995). The approach for developing this vaccine is similar to the one used by Merck Sharp \& Dohme B.V. for Ervebo ${ }^{\circledR}$, a vaccine developed against Ebola virus, in which the VSV-G was replaced by that of Zaire Ebola Virus Kikwit 1995 strain glycoprotein (Suder et al. 2018). The efficacy of the vaccine was demonstrated using the golden Syrian hamster in-vivo model for COVID-19, where it was shown that a single-dose vaccination with the rVSV- $\Delta$ G-SARS-CoV-2-S vaccine resulted in a rapid and potent induction of SARS-CoV-2 neutralizing antibodies. In addition, vaccination protected hamsters against SARSCoV-2 challenge. This was evident in immunized, compared to unvaccinated, hamsters by the abrogation of body weight loss, as well as alleviation of extensive tissue damage and reduced viral loads in the lungs and nasal turbinates (Yahalom-Ronen et al. 2020).

To evaluate the safety profile of the rVSV- $\Delta$ G-SARSCOV-2-S vaccine, and to support its clinical development and licensure, a series of nonclinical safety, immunogenicity and efficacy (potency) studies were performed. In this work, we present the results of the nonclinical safety and immunogenicity studies conducted in four species; mouse, hamster, rabbit and pig. The design of the studies was based on the principles described in the WHO Guideline of Nonclinical Evaluation of Vaccines-Annex 1 (Available on line https:// www.who.int/publications/m/item/annex 1-nonclinical.p3163), which is recognized by both FDA and EMA as well as by the EMA Guideline on quality, non-clinical and clinical aspects of live recombinant viral-vectored vaccines (Available on line https://www.ema.europa.eu/en/quality-non-clini cal-clinical-aspects-live-recombinant-viral-vectored-vacci nes), and included single- and repeated-dose studies. In addition, attention was given to potential risks that may be associated with viral-vectored vaccines, including the potential for neurovirulence, vaccine shedding, vaccine replication and potential distribution to tissues of interest.

\section{Materials and methods}

\section{Virus and vaccine}

Generation of the pVSV $\Delta$ G-S construct was described in detail, previously (Yahalom-Ronen et al. 2020). Briefly, the pVSV-spike expression plasmid was constructed by PCR amplification of the full-length human codon-optimized S gene from pCMV3-SARS-CoV-2 S expression 
plasmid (Sino Biological, Cat\# VG40588-UT) that was used to replace the VSV-G (Glycoprotein) open reading frame within the VSV full-length expression vector, yielding pVSV- $\Delta$ G-spike. Primary recovery of the rVSV- $\Delta$ GSARS-CoV-2-S was performed in BHK-21 cells infected with Modified Vaccinia Ankara T7 (MVA-T7), followed by co-transfection with the rVSV-SARS-CoV-2-S, and the VSV accessory plasmids encoding for VSV-N, P, L and G proteins under control of a $\mathrm{T} 7$ promoter. Recovered $\mathrm{rVSV}-\Delta \mathrm{G}$-spike was collected, centrifuged, and used for further passaging. Fourteen subsequent passages on Vero E6 cells were performed, aimed to eliminate the carryover of the VSV-G protein used during the initial recovery steps, and to increase the viral replication efficiency and titer. Stock virus for vaccination was propagated on Vero E6 cells, concentrated using $10 \%$ polyethylene Glycol (PEG, Sigma) $8000-0.5 \mathrm{M} \mathrm{NaCl}$ $(\mathrm{V} / \mathrm{V})$ for $1 \mathrm{~h}$ at $11,000 \mathrm{rcf}$. The pellet was re-suspended in PBS containing $15 \mathrm{mM}$ D-Trehalose (Sigma). The virus stock was titrated on Vero E6. Aliquots for single use were stored in $-80^{\circ} \mathrm{C}$ for further use.

\section{Animals}

C57BL/6 J, knockout for type I interferon (IFN) receptors (Ifnar-/-) and hACE2-K18 mice were obtained from The Jackson Laboratory, USA, and were 6-12 weeks of age at study initiation. Golden Syrian hamsters were obtained from Charles River, USA, and were 6-7 weeks of age at study initiation.

Female New Zealand White (NZW) rabbits were obtained from Charles River, France, and were 14-16 weeks of age at study initiation. Female pigs (Topigs 20, a cross between the $\mathrm{Z}$ line, Large-White dam and the $\mathrm{N}$-line, Landrace) were obtained from Van Beek, Netherlands, and were 9-10 weeks of age at study initiation.

Animals were housed in group cages in a biosafety level 2 (BSL-2) containment facility, maintained at room temperature between 18 and $24{ }^{\circ} \mathrm{C}$ and 30 to $70 \%$ relative humidity, with a 12-h light/12-h dark cycle. Animals received a pelleted diet. Mice, hamsters and rabbits had free access to food and water throughout all the studies. Pigs were fed twice a day ( $4 \%$ of their body weight daily) and allowed free access to drinking water supplied by automated watering valves.

\section{Ethics statement}

Experiments were approved by the IIBR animal care and use committee (IACUC) and performed by trained peroneal at IIBR in accordance with the guidelines of the care and use of laboratory animals published by the Israeli Ministry of Health (protocols: mice C57BL/6J \# No. M-52-20, Ifnar1 knock-out and hACE2-K18 mice \# No. M-65-20, hamster \# No. HM-02-20, rabbits \# No. RB-13-29, pigs \# No.
P-03-20). All efforts were made to minimize animal suffering. All animals were observed for morbidity and mortality, overt signs of toxicity (including abstinence from food and water), and any signs of distress throughout the studies.

\section{Procedures and examinations}

\section{Animal vaccination}

Golden Syrian hamsters were vaccinated by a single i.m. injection (hind shin, left leg) at a dose of $0(n=8)$ or $10^{6}$ Plaque-forming unit (PFU), $(n=20)$ and at a dose volume of $0.05 \mathrm{ml} /$ animal.

Four groups of rabbits ( $n=4$ females/group) were vaccinated by two successive i.m. injections of $0,10^{6}, 10^{7}$ or $10^{8}$ PFU respectively (shin area of left leg), at a dosing interval of two weeks and at a dose volume of $1 \mathrm{ml} / \mathrm{animal}$ (full human dosing volume).

Three groups of pigs ( $n=2$ females/group) were vaccinated by two successive i.m. injections of $0,10^{6}$ and $10^{8}$ $\mathrm{PFU}$, respectively (alternating thigh muscles) at a dosing interval of two weeks and at a dose volume of $1 \mathrm{ml} / \mathrm{ani}$ mal (full human dosing volume). To mark the injection area boundaries, a circle was marked by a durable marker and photographed. Body weight, general observations and local reactions at injection sites were monitored throughout each study period. Body temperature was also measured in rabbits and pigs.

Control animals were injected with carrier buffer (PBF solution; PBS containing $2 \%$ fetal bovine serum) at an identical dose volume and under identical experimental conditions.

\section{Immunogenicity and cellular immunity determination}

The immunogenicity of the vaccine was evaluated by determining 50\% SARS-CoV-2 neutralization titer by plaque reduction neutralization test (PRNT), as described in detail, previously (Yahalom-Ronen et al. 2020). Briefly, Vero E6 cells were seeded in 12-well plates. Heat-inactivated sera $\left(56{ }^{\circ} \mathrm{C}\right.$ or $60{ }^{\circ} \mathrm{C}$ for $30 \mathrm{~min}$ ) were diluted in twofold serial dilutions (between 1:20 and 1:40,960) in $400 \mu \mathrm{l}$ of infection medium, mixed with $400 \mu \mathrm{l}$ of $300 \mathrm{PFU} / \mathrm{ml}$ SARS-CoV-2, and incubated at $37{ }^{\circ} \mathrm{C}, 5 \% \mathrm{CO}_{2}$ for $1 \mathrm{~h}$. Virus mixture without serum served as control. Monolayers were washed once with DMEM w/o FBS (for SARS-CoV-2 neutralization only) and $200 \mu \mathrm{l}$ of each serum-virus mixture was added in triplicates to the cells. Plates were incubated for $48 \mathrm{~h}\left(37^{\circ} \mathrm{C} 5 \%\right.$ $\mathrm{CO}_{2}$ ), and cells were fixed and stained $(1 \mathrm{ml} /$ well of crystal violet solution). The number of plaques in each well was determined and NT50 was calculated using Prism software (GraphPad Software Inc.) 
Cellular immunity was analyzed in vaccinated and naïve pigs. Peripheral blood mononuclear cells (PBMC) were stimulated for $48 \mathrm{~h}$ in the presence of spike protein $(0,1$ or $10 \mu \mathrm{g}$ ) (Noy-Porat et al. 2020). Interferon $\gamma$ (IFN $\gamma$ )-secreting cells were enumerated with Pig IFN- $\gamma$ Single-Color ELISPOT kit (ImmunoSpot, CTL Technologies, Germany) with strict adherence to the manufacturer's instructions. The frequency of cytokine-secreting cells was quantified with an ImmunoSpot S6 reader and analyzed with ImmunoSpot software (ImmunoSpot, Cellular Technology Limited, Germany). Secreted cytokine (IL-2, IFN $\gamma$, IL-4, IL-10) concentrations were determined with MILLIPLEX MAP Porcine Cytokine/Chemokine Magnetic Bead Panel (Merck-Millipore) with strict adherence to the manufacturer's instructions. ConA ( $2 \mu \mathrm{g} / \mathrm{ml}$, Sigma-Aldrich) served as a positive control for the stimulation, in which for all the examined samples the spot count was higher than 800 spots per $10^{6}$ PBMC.

\section{Hematology, biochemistry, coagulation, viremia and viruria}

Blood was collected from rabbits and pigs via the central (auricular) artery or the marginal ear veins, after applying local anesthesia to the outer ear (e.g., Emla 2.5\% Topical Cream, applied $30 \mathrm{~min}$ prior to blood sampling) and following mild pre-heating of the animal environment ( $\sim 5 \mathrm{~min})$. Blood for hematology was collected in EDTA tubes (inverted and stored on wet ice); blood for biochemistry was collected in serum separator tubes. The serum was allowed to clot at room temperature for at least half an hour; blood was centrifuged at $1000 \mathrm{~g}$ for $15 \mathrm{~min}$ and serum poured off into two labeled $1.2 \mathrm{~mL}$ cryogenic vials, immediately analyzed or frozen at, or below, $-70^{\circ} \mathrm{C}$ for future analysis (viremia).

For hematological analysis, a complete blood count, including platelet and differential count was performed on the day of collection (Oxford Science GenX, USA). For clinical biochemistry, serum samples were evaluated for the following: albumin, alkaline phosphatase alanine aminotransferase, amylase, total bilirubin, blood urea nitrogen, calcium, phosphorous, creatinine, glucose, sodium, potassium, total protein and globulin. For coagulation, serum samples were evaluated for the following endpoints: prothrombin time (PT), partial prothrombin time (PTT) and fibrinogen (Abaxis-Vet Scan VS2, USA).

Whole blood and urine samples were collected for assessment of viremia and viruria, respectively, at several time points (see "Results" section). Whole blood was collected using the same procedures as described above, and urine samples were collected from the cage's tray. Samples were prepared as follows: $200 \mu \mathrm{l}$ of urine or blood sample was added to $150 \mu \mathrm{l}$ of lysis buffer (LBF, supplied with the extraction kit) and incubated for $20 \mathrm{~min}$ at room temperature to complete lysis. Following lysis, RNA extraction was completed using an RNAdvance Viral kit as per manufacturer's instructions. Real-time RT-PCR was performed using the SensiFASTTM Probe Lo-ROX one-step kit. In each reaction, the primers final concentration was $600 \mathrm{nM}$ and the probe concentration was $300 \mathrm{nM}$. Primers and probes were designed using the Primer Express Software (Applied Biosystems), targeting: (1) the native Nucleocapsid gene (N) of Vesicular Stomatitis Virus Indiana strain and (2) the human codon-optimized SARS-CoV-2 Spike gene (S). Thermal cycling was performed at $48{ }^{\circ} \mathrm{C}$ for $20 \mathrm{~min}$ for reverse transcription, followed by $95{ }^{\circ} \mathrm{C}$ for $2 \mathrm{~min}$, and then 45 cycles of $94{ }^{\circ} \mathrm{C}$ for $15 \mathrm{~s}, 60^{\circ} \mathrm{C}$ for $35 \mathrm{~s}$. Thermal cycling conditions were taken from the Berlin protocol published in the WHO recommendation for the detection of SARS-CoV-2 (Corman et al. 2020).

\section{Primers and probes}

N gene: forward: TGATCGACTTTGGATTGTCTTCTAA, reverse: TCTGGTGGATCTGAGCAGAAGAG, probe: ATATTCTTCCGTCAAAAACCCTGCCTTCCA; S gene: forward: GAGTGAGTGTGTGCTGGGACAA, reverse: AAACACTCCCTCCCTTGGAAA, probe: AGTTTTCCACAGTCTGCCCCTCATGGA.

The probes used were 6-FAM and ZEN/Iowa Black FQ combination. Assay performance was verified using appropriate controls.

\section{Macroscopic and histopathological examinations}

Hamsters were euthanized and the following organs: brain, heart, lung, liver, kidney, colon and the shin-injection site were collected. Organs were fixed in $4 \%$ formaldehyde, trimmed in a standard position per organ and placed in embedding cassettes. Paraffin blocks were sectioned at approximately four microns thickness. The sections were placed on glass slides and stained with Hematoxylin \& Eosin (H\&E). Histopathological evaluation of the slides was performed by PATHO-LOGICA Ltd.

Rabbits and pigs were subjected to a full detailed necropsy and gross pathological examination following the respective scheduled termination. At necropsy, all animals were thoroughly examined, including the external surface of the body, all orifices, cranial, thoracic and abdominal cavities and their contents. Any abnormalities or gross pathological changes observed in tissues and/or organs were recorded accordingly. All organs/tissues were collected from all animals during necropsy and fixed in 10\% neutral-buffered formalin (approximately 4\% formaldehyde solution) apart from the eyes, which were fixed in Davidson's solution. All organs/tissues were trimmed, embedded in paraffin, sectioned at approximately five micron thickness and stained 
with Hematoxylin \& Eosin (Alizée Pathology, Inc). The slides were subjected to histopathological evaluation by a board-certified toxicologic pathologist, using state-of-theart recommended morphological criteria published by the International Harmonization of Nomenclature and Diagnostic Criteria (INHAND), https://www.toxpath.org/inhand.asp. A grading scheme, derived from Schafer et al. (Schafer et al. 2018), was used to evaluate pathologic lesions in the tissues as follows: no lesion (0), minimal (grade 1), mild (grade 2), moderate (grade 3 ) and marked (grade 4).

\section{Vaccine replication in the $\mathrm{K} 18 \mathrm{hACE} 2$ transgenic mouse model}

Animals were euthanized by cervical dislocation immediately following vaccination (time 0 ), 24, 48 and $72 \mathrm{~h}$ post vaccination ( $n=4$ mice per time point). The site of injection and the lungs were excised, then snap-frozen (liquid nitrogen followed by storage at $-70^{\circ} \mathrm{C}$ ). The organs were homogenized for $30 \mathrm{~s}$ in ice cold PBS $(1.5 \mathrm{ml})$ sonicated $(3 \mathrm{X}, 30 \mathrm{~s})$ centrifuged $\left(270 \mathrm{~g}, 10 \mathrm{~min}, 40^{\circ} \mathrm{C}\right)$ and supernatants were collected for virus titration on Vero-E6 cells, as described previously (Israely et al. 2012). Briefly, samples were serially diluted and allowed to adsorb to Vero-E6 cells for $1 \mathrm{~h}$ at $37^{\circ} \mathrm{C}$ on a reciprocal rocker, then overlaid with a sterile Gum-Tragacanth (Merck) overlay. The infected cultures were incubated, uninterrupted, at $37{ }^{\circ} \mathrm{C}$ in a $5 \% \mathrm{CO}_{2}$ incubator for 3 days, then aspirated, fixed and stained for five minutes at room temperature with a crystal violet solution ( $0.1 \% \mathrm{~W} / \mathrm{V}$ crystal violet (Merck) in 20\% Ethanol). The cells were washed with tap water, dried, and PFU were counted.

The limit of detection (LOD) was determined based on the volume used for cell infection $(0.2 \mathrm{ml} /$ well $)$, dilution factor, and tissue processing volume (e.g., $1 \mathrm{ml}$ per organ). The LOD (PFU/organ) was calculated based on an average of one plaque at the minimal possible dilution (for most tissues 1:10 from the undiluted tissue) multiplied by the dilution factor and volumes.

\section{Neurovirulence testing}

VSV-WT or rVSV- $\Delta$ G-SARS-CoV-2-S vaccines were injected intracranially (i.c.) to C57BL/6 immune competent mice (6-12 weeks old, $n=3 /$ dose level) and to type I interferon receptor knock-out (IFNAR KO) mice (6-12 weeks old, $n=3$ /dose level) at a dosing volume of $30 \mu \mathrm{l}$.

Naïve mice were injected with the formulation buffer only ( $n=3$ /group for each mouse strain) and were used as controls. For i.c. viral injection, mice were anesthetized (Ketamine $75 \mathrm{mg} / \mathrm{kg}$, Xylazine $7.5 \mathrm{mg} / \mathrm{kg}$ in PBS) and injected with 30 $\mu \mathrm{L}$ of the examined virus diluted in PBS $+2 \%$ heat-inactivated fetal calf serum (or formulation buffer alone), using a $27-\mathrm{G}$ needle into the right frontal cerebral hemisphere. Penetration of the needle was restricted to a depth of 2 to $3 \mathrm{~mm}$ (Israely et al. 2019). Mice were monitored daily for morbidity for 14 consecutive days. For histopathology evaluations, rVSV- $\Delta \mathrm{G}$ SARS-CoV-2-S C57BL/6 ( $n=3)$, rVSV- $\Delta$ G-SARS-CoV-2-S IFNAR $(n=6)$ or VSV-WT C57BL/6 $(n=5)$ i.c. injected mice were sacrificed on day 14,14 and 2, respectively. In addition, vehicle-injected ( $n=3 /$ strain) and naïve ( $n=3 /$ strain) mice were sacrificed on day 14 and served as controls. Mice were sedated, perfused and fixed with $4 \%$ formaldehyde, and brains were collected and fixed with $4 \%$ formaldehyde for histopathological examination. Paraffin blocks were transversely sectioned at approximately four microns thickness. For each brain, three transverse sections were cut at the level of the striatum $(\mathrm{Sr})$, hippocampus $(\mathrm{Hc})$ and cerebellum $(\mathrm{C})$, to include the frontal cortex $(\mathrm{FC})$, striatum $(\mathrm{Sr})$, thalamus $(\mathrm{TH})$, hypothalamus $(\mathrm{H})$, hippocampus $(\mathrm{Hc})$ and cerebellum $(\mathrm{C})$. Sections were placed on glass slides and stained with $\mathrm{H} \& \mathrm{E}$ for general histopathology. The slides were evaluated by the IIBR histology unit. H\&E-stained sections were examined and graded according to a semi-quantitative scoring scale for the presence and severity of pathological changes. Histopathologic changes consistent with neurovirulence were scored in a double-blinded manner, based on the presence and severity of perivascular infiltrates, gliosis, neurodegeneration, satellitosis, and necrosis. Cumulative assessment of all changes was scored on a severity scale of $0-4$, based on previously published work (Mire et al. 2012).

\section{Statistical analysis}

Data were analyzed with GraphPad Prism 6 software or with SPSS (V25) software. Body weight changes (hamsters) were analyzed according to the Holm-Sidak method, with alpha $=5.000 \%$. Body weights (rabbits) were normalized to baseline using a mixed model ANOVA, with time post exposure as a repeated within subject factor, and the different groups as a between subject factor. A Greenhouse-Geisser correction for violation of sphericity was used. Body temperature (rabbits) was analyzed using a separate one-way ANOVA for each of the time points examined. ANOVA results indicating a significant difference between groups were followed up further, post hoc, by comparing each of the vaccinated groups to control group, using (2-sided) Dunnett's $t$ tests.

\section{Results}

\section{rVSV- $\Delta$ G-spike vaccine safety in a COVID-19 hamster model}

We recently reported that a single-dose vaccination with rVSV- $\Delta$ G-SARS-CoV-2-S vaccine resulted in a rapid and 
potent induction of SARS-CoV-2 neutralizing antibodies in a golden Syrian hamster model, and protected hamsters against SARS-CoV-2 challenge (Yahalom-Ronen et al. 2020). We further utilized this model to evaluate the safety of the candidate vaccine, in three groups of female Syrian hamsters. One group of hamsters ( $n=20$ females) was administered with rVSV- $\Delta$ G-SARS-CoV-2-S vaccine by a single i.m. injection at a dose of $10^{6} \mathrm{PFU}$ and at a dose volume of $0.05 \mathrm{ml} /$ animal. A vehicle control group $(n=4$ females) was administered with the carrier buffer (PBF solution) and a naïve control group ( $n=4$ females) served as an additional control group. The dose of $10^{6} \mathrm{PFU}$ was selected as it was shown to be immunogenic and protective in this model (Yahalom-Ronen et al. 2020). Following administration of rVSV- $\Delta$ G-SARS-CoV-2-S vaccine, no treatment-related mortality, nor noticeable systemic or local reactions were noted in any of the animals throughout the 24-day observation period. The vaccinated animals exhibited mean group body weight gain similar to that of the control groups, seven days post vaccination (Fig. S1, Table 1). Histopathological evaluation carried out seven days post vaccination revealed no treatment-related pathological, cytotoxic or other adverse effects in the tested organs (brain, heart, lung, liver, kidney, colon and the shin-injection site) in all treated animals. Blood samples were obtained from five vaccinated hamsters, 20 days post vaccination for determination of neutralizing antibody titer. Neutralizing antibodies were detected in all vaccinated hamsters, although high variability was observed $(n=5$, Mean $=2371, \mathrm{SEM}=806.6$ Range: 301.9-5133. Fig. S2). Taken together, a single-dose vaccination of hamsters with rVSV- $\Delta$ G-SARS-CoV-2-S vaccine $\left(10^{6} \mathrm{PFU} / \mathrm{animal}\right)$ was found to be safe and immunogenic and did not lead to any treatment-related histopathological changes in the main organs tested (data not shown).

\section{Safety and immunogenicity in NZW rabbits}

Four groups of female NZW rabbits ( $n=4$ females/group) were tested. Three groups were vaccinated with rVSV$\Delta$ G-SARS-CoV-2-S vaccine at dose levels of $10^{6}, 10^{7}$ or $10^{8} \mathrm{PFU}(1 \mathrm{ml} / \mathrm{animal} /$ injection). An additional group was injected with the vehicle and served as control. All animals were subjected to two repeated i.m. vaccinations (prime and boost) at an interval of two weeks, and follow-up continued for an additional 21-day recovery period (total observation period of 35 days). Body weight, general observations, local reactions at injection sites and body temperature were monitored throughout the study period. No mortality occurred and no noticeable systemic or local reactions were noted in any of the animals throughout the 35-day study period (Table 1). All rVSV- $\Delta$ G-SARS-CoV-2-S vaccine-treated groups exhibited increased body weight gain comparable to that of the control group, consistent with young animal growth (Fig. 1a) and no statistically significant differences were noted in all vaccine-treated groups vs. control. Mean group body temperature values of all groups were within the normal range throughout the seven days post-prime and post-boost vaccinations (i.e., no signs of hypothermia or hyperthermia). Statistically significant differences $(p<0.05)$ were noted at several time points between vaccine-treated groups vs. control $\left(10^{6} \mathrm{PFU}\right.$ : Day 0; $10^{7} \mathrm{PFU}$ : Day 0, 21; $10^{8}$ PFU: Day 17, 21); however, as in all cases, the measured values were within the normal ranges (i.e., $38-40{ }^{\circ} \mathrm{C}$ ); these differences were deemed as normal physiological variation as per the breeder model information sheet (New Zealand White Rabbits. Available on line https://www.criver.com/ sites/default/files/resources/rm_rm_d_NZW_rabbit.pdf) (Fig. 1b).

Serum samples were collected on day 14 (prior to vaccination boost) and on day 31, 17 days after the vaccination boost and analyzed for the presence of neutralizing antibodies against SARS-CoV-2. Dose-response dependency in mean group neutralizing antibodies was evident following each vaccination session and mean group NT50 was increased in response to the boost vaccination in the low- and medium-dose groups. Following vaccination with the high dose $\left(10^{8} \mathrm{PFU}\right)$, neutralizing titers were efficiently induced following prime vaccination, and boost vaccination did not significantly affect the neutralization titer (Fig. 1).

Hematology, biochemistry and coagulation parameters were assessed at several time points. In all vaccinated groups, these parameters were found to be similar to the baseline or control animals' values throughout the study period. The potential for viral shedding in urine samples (viruria), whole blood and serum (viremia) was tested to evaluate the extent of the vaccine dissemination from the site of administration, the rapidity of its clearance and its potential dissemination through secretions. No evidence of viremia was noted in any of the serum samples obtained three and seven days post the prime vaccination, in addition, no shedding of viral vaccine was detected on day three post the prime vaccination in any of urine samples collected (data not shown).

At necropsy, 21 days post second vaccination, no treatment-related macroscopical findings or changes in organ weight and organ to body weight ratio values were evident in any of the vaccine-treated animals. Histopathological evaluation revealed treatment-related changes in all treated groups, generally being dose-related in incidence and/or severity, and which corresponded to the pharmacological activity of the vaccine. The changes were seen at the injection sites, regional iliac lymph nodes and spleen (Fig. 2).

The changes at the injection sites consisted of multifocal minimal myofiber necrosis (limited to the 2 higher doses); multifocal minimal- to mild-mixed inflammatory cell infiltration (i.e., cells consisting of a mixture of 


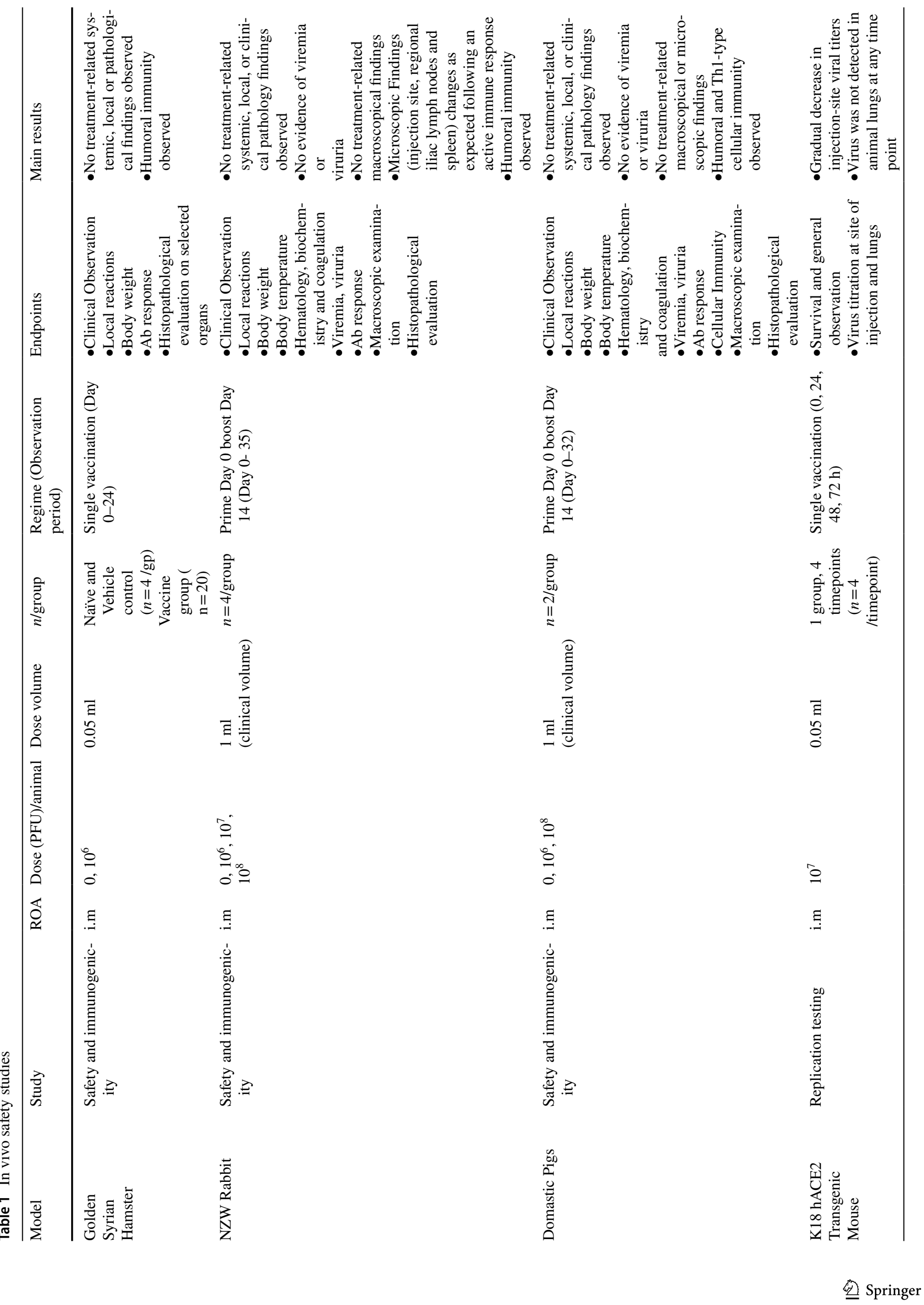




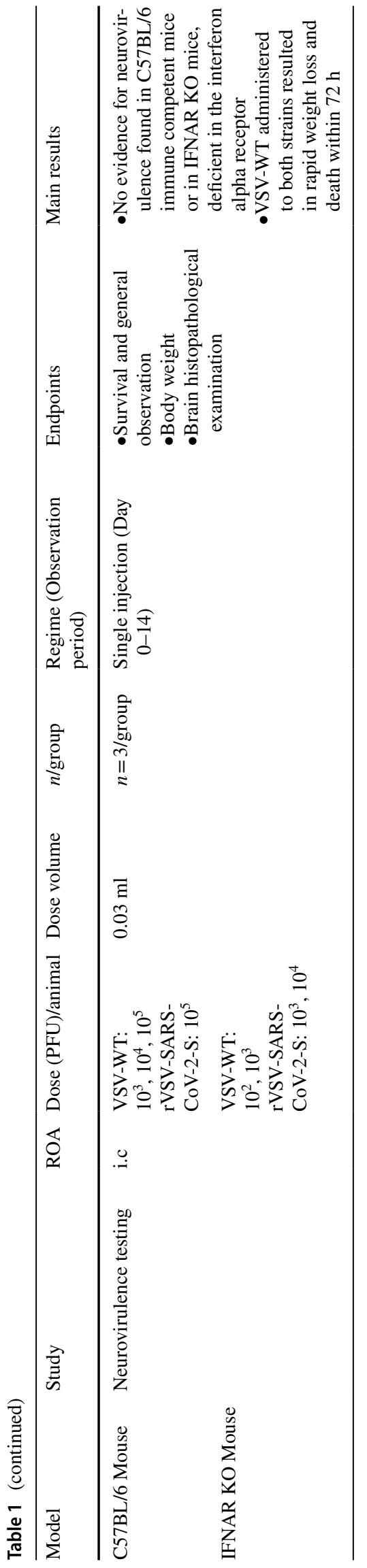

polymorphonuclear cells, lymphocytes and macrophages within the skeletal muscle and/or interstitial fat tissue) and focal minimal granulomatous inflammation (seen in a single Low-dose and in a single High-dose animal). This inflammatory reaction was also seen in the fat tissue surrounding the sciatic nerve, but did not extend into the sciatic nerve itself. This change is considered an extension of the primary injection-site inflammation, possibly related to the needle location/insertion and is not considered to reflect any increase in local irritation (Fig. 2a, b).

In the spleen, minimal to mild germinal centers increased lymphocytic cellularity (i.e., follicular hyperplasia) were noted (Fig. 2c, d). In the iliac lymph nodes (i.e., regional lymph node to the injection site), mild to moderate germinal centers increased lymphocytic cellularity (i.e., follicular hyperplasia) were seen in all treated groups (Fig. 2e, f). The germinal centers increased lymphocytic cellularity (i.e., follicular hyperplasia), seen in spleen and iliac lymph nodes, is considered to reflect a secondary change due to antigenic stimulation of the test compound (Willard-Mack et al. 2019), and were reported previously in rabbits exposed to vaccination (Baldrick 2016).

\section{Safety and immunogenicity in domestic pigs}

In this study, two groups of female Topig-20 pigs $(n=2$ females/group) were vaccinated with rVSV- $\Delta$ G-SARSCoV-2-S vaccine at dose levels of $10^{6}$ and $10^{8} \mathrm{PFU}(1 \mathrm{ml} /$ animal, in a single injection site). An additional group $(n=2$ females) was injected with the carrier buffer and served as control. Similar to the rabbit study, the pigs were subjected to two repeated i.m. vaccinations (prime and boost) at an interval of two weeks, with follow-up continued for an additional 18-day recovery period (total observation period of 32 days). No mortality occurred and no noticeable systemic or local reactions were noted in any of the animals throughout the 32-day study period (Table 1). All rVSV- $\Delta$ G-SARS$\mathrm{CoV}-2-\mathrm{S}$ vaccine-treated groups exhibited increased body weight gain comparable to that of the control group, consistent with young animal growth (Fig. 3a), and the temperature profile of all animals was within the normal range (i.e., no signs of hypothermia or hyperthermia; Fig. 3b) (Hannon et al. 1990).

Blood samples for immunogenicity were collected on day 14 (prior to vaccination boost) and on day 31, 17 days after the vaccination boost. These samples were analyzed for the presence of neutralizing antibodies and for cellular immunity responses.

A positive association was found between the neutralization antibodies levels and the stimulation of the cellular immunity. Both rVSV- $\Delta$ G-SARS-CoV-2-S vaccine doses induced a neutralization response (Fig. 3c) and an increase in $\mathrm{T}$ cell response to spike protein (Fig. 4). 
(a)

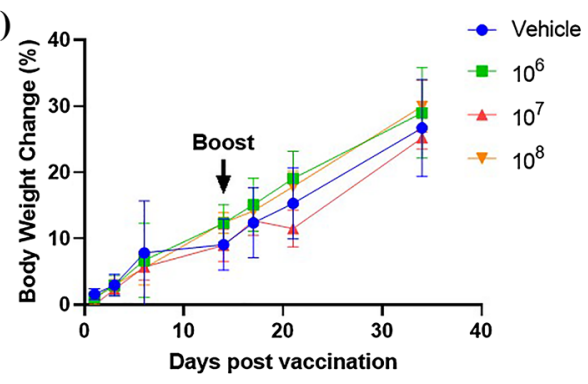

(b)

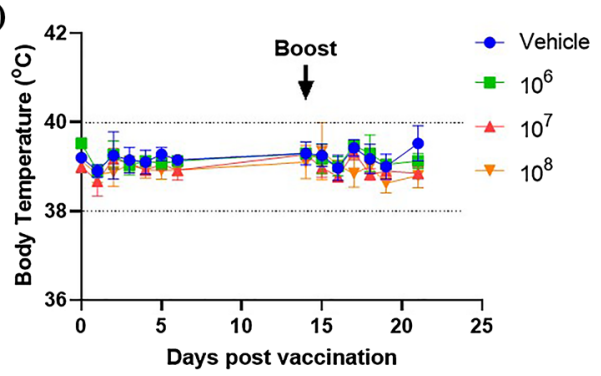

(c)

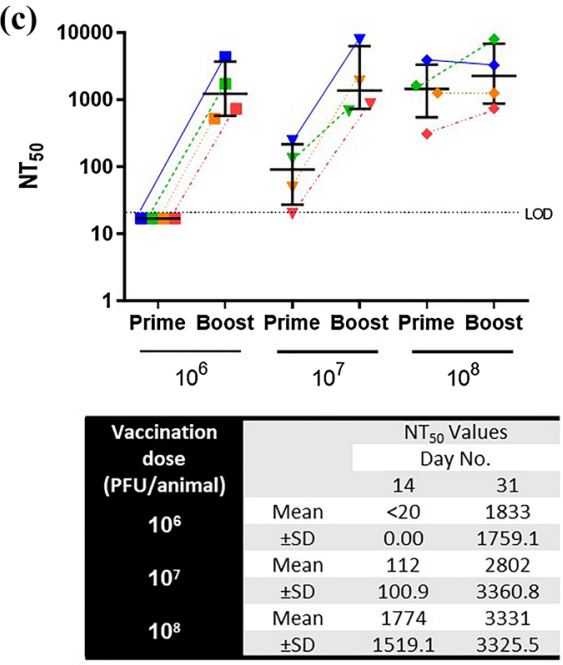

Fig. 1 Body weight, temperature and serum neutralizing antibody titers in rabbits after prime/boost vaccination. a Body weight change percentage compared between groups ( $n=4$ /group). b Group mean body temperature $\left({ }^{\circ} \mathrm{C}\right)$ following prime and boost vaccination of rabbits. Dashed lines indicate normal body temperature range. c Vaccinated rabbit sera neutralization assay results [mean group NT50,

Significant levels of IFN $\gamma$-secreting cells were observed among all the vaccinated pigs, up to $4 \times 10^{3}$ cells per $10^{6}$ PBMC, following boost. The boost effect was observed in all the vaccinated animals, in accordance with increased neutralization antibodies levels (Fig. 4a). Interleukin-2 and $\mathrm{TNF} \alpha$ secretion were evident following spike antigenic stimulation in all the vaccinated pigs, with no IL-4 and marginal IL-10 secretion, indicative of a clear Th-1 response, (Fig. 4b). Hematology, biochemistry and coagulation parameters were assessed at several timepoints throughout the study and were generally similar to baseline values or to control animals' values. There was no evidence of viremia in either whole blood (day 2 and 31) or serum (day $2,7,14$ and 31 ), or viral shedding in urine samples (day $2 / 3$ and $7 / 8$ ) throughout the study period.

At necropsy and histopathology evaluation, no treatment-related findings were observed. Sporadic minimal spontaneous lesions were noted in the liver, i.e., minimal inflammatory cell infiltration. Such changes are reported to occur spontaneously in pigs/minipigs. In the spleen and lungs, congestion was noted, which was comparable in control and treated animals and are well known to be associated with barbiturate injection for euthanasia (Grieves et al. 2008), the termination technique used in this experiment.

\section{Replication of rVSV- $\Delta$ G-SARS-CoV-2-S vaccine in K18 hACE2 transgenic mice}

To further evaluate the safety of rVSV- $\Delta$ G-SARS-CoV$2-S$ vaccine, the ability of the vaccine to propagate at the site of injection and to spread to the lungs was assessed in K18-hACE2 transgenic mice in which the human ACE-2 receptor (hACE2) is expressed under the K18 promotor in all epithelial cells. K18-hACE2 transgenic mice are considered to be a highly sensitive animal model for SARS-CoV-2 (Golden et al. 2021; Yinda et al. 2021; Zheng et al. 2021), and were also shown to induce neutralizing antibodies in response to rVSV- $\Delta$ G-SARS-CoV-2-S vaccination (manuscript in preparation). Mice were vaccinated i.m. in the right shin limb with $10^{7} \mathrm{PFU}$ in a volume of $0.05 \mathrm{ml}$, and were euthanized immediately following vaccination (time 0$), 24$, 48 and $72 \mathrm{~h}$ post vaccination $(n=4$ mice per time point, Table 1). The site of injection and the lungs were collected and processed, and infectious virus was quantified by plaque assay, as described above (Noy-Porat et al. 2020; YahalomRonen et al. 2020).

A gradual decrease in the viral titer was observed at the site of injection (Fig. 5). Out of the injected $10^{7} \mathrm{PFU}$, an average of $4.1 \times 10^{6}(41 \%)$ was recovered immediately after injection. This reduction can be attributed to the 

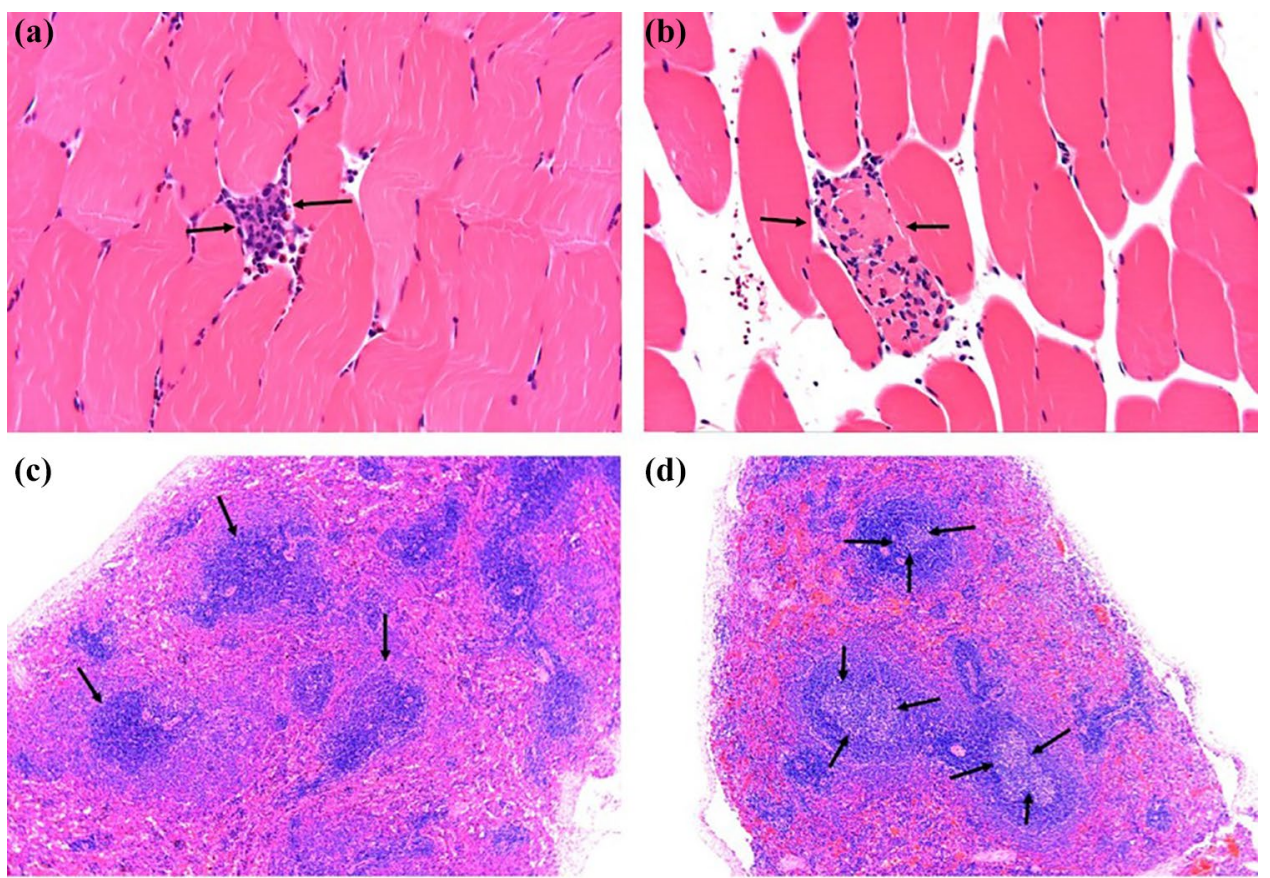

(e)

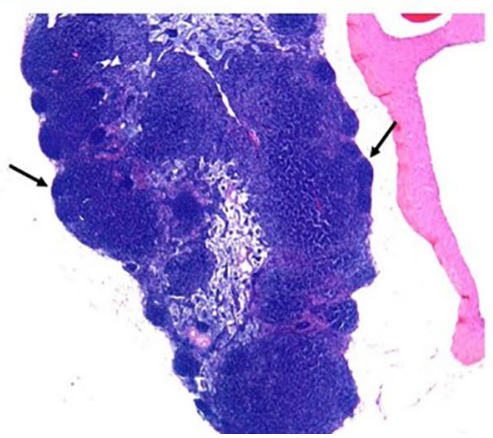

Fig. 2 Rabbit histopathology following prime/boost vaccination. Histopathological evaluation performed 3 weeks post second-vaccination session. a-b Injection-Site Analysis (high dose, $10^{8}$ PFU/animal)arrows indicate changes at the injection sites consisting of focal minimal mixed inflammatory cell infiltration $(\mathbf{a})(\times 100)$ and focal minimal muscle fiber necrosis associated with mixed inflammatory cell infiltration $(\mathbf{b})(\times 400)$ which are not considered as adverse treatment effects. c Spleen of control animal $(\times 100)$ and $\mathbf{d}$ high dose $\left(10^{8} \mathrm{PFU}\right)$ animal $(\times 100)$ : arrows indicate minimal to mild germinal centers increased lymphocytic cellularity (i.e., follicular hyperplasia), noted

technical procedures performed on all organs following retrieval. The viral load then gradually reduced, reaching an over $4-\log$ reduction after $72 \mathrm{~h}(0.003 \%$ of the dose observed at time zero). Virus was not detected in the lungs at any time point, in any of the animals. These results demonstrate the existence of the vaccine at the site of injection and its gradual clearance (over three days), but also show that there was still viable virus up to $72 \mathrm{~h}$ post vaccination in some of the animals - a time window which allows for formation and induction of a robust immune response. (d)
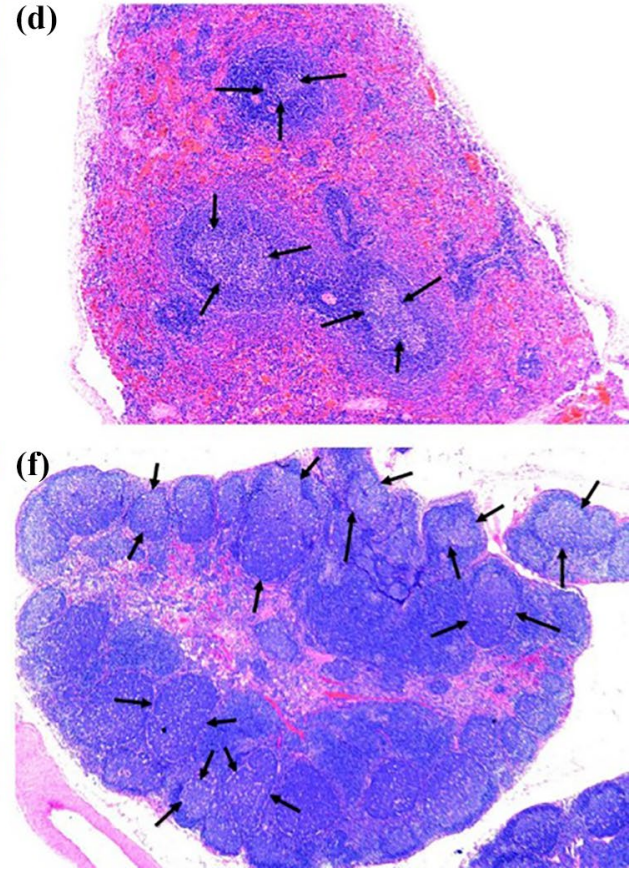

following vaccination and considered to reflect a secondary change due to antigenic stimulation. No evidence of germinal centers was observed in a control animal (c). e Iliac Lymph Node (regional lymph node to the injection site) of control animal $(\times 40)$ and $(\mathbf{f})$ of the high dose $\left(10^{8}\right.$ PFU) animal $(\times 40)$ : arrows indicate mild to moderate germinal centers increased lymphocytic cellularity (i.e., follicular hyperplasia), noted following vaccination and considered to reflect a secondary change due to antigenic stimulation. No evidence of germinal centers was observed in a control animal (e)

\section{Neurovirulence in mice}

Several studies in cultured cells and mice demonstrated the role of VSV-G as a major virulent component of wild-type VSV, mediating infection of neurons and neurovirulence in mice. Consequently, when VSV-G was eliminated and replaced with a heterologous viral surface protein, neurovirulence was abrogated (Muik et al. 2011, 2014). In ERVEBO $^{\circledR}$, elimination of VSV-G and replacing it with the glycoprotein (GP) of Ebolavirus (rVSV-ZEBOV-GP) 
Fig. 3 Body weight, temperature and serum neutralizing antibody titers in pigs after prime/boost vaccination. a Individual body weight change (percentage). b Individual body temperature $\left({ }^{\circ} \mathrm{C}\right)$ following prime and boost vaccination of pigs. Dashed lines indicate normal body temperature range. c Individual pig sera neutralization assay results (mean group NT50, using plaque reduction neutralization test (PRNT). Sera were collected on day 14 (14 days post first vaccination; "prime") and on day 31 ("boost"). Error bars show median interquartile range (IQR)
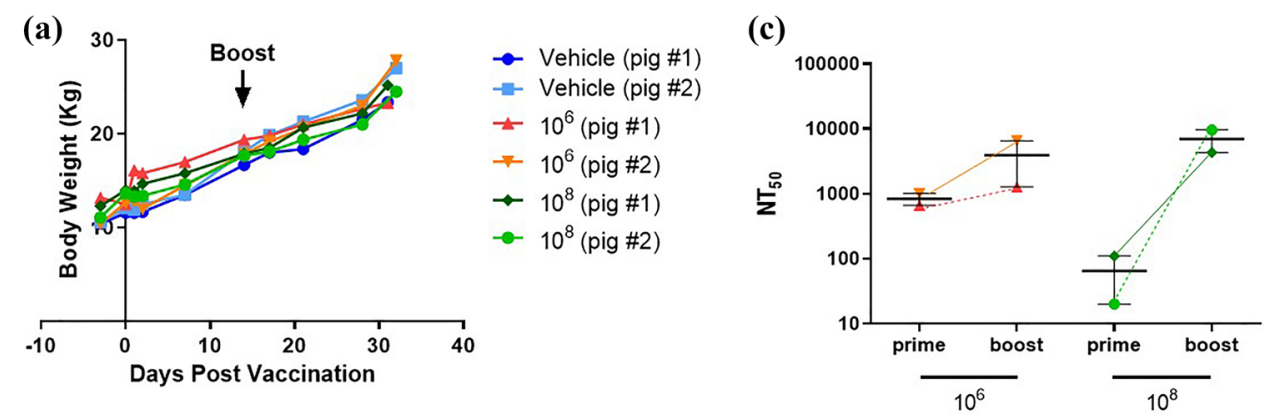

(b)
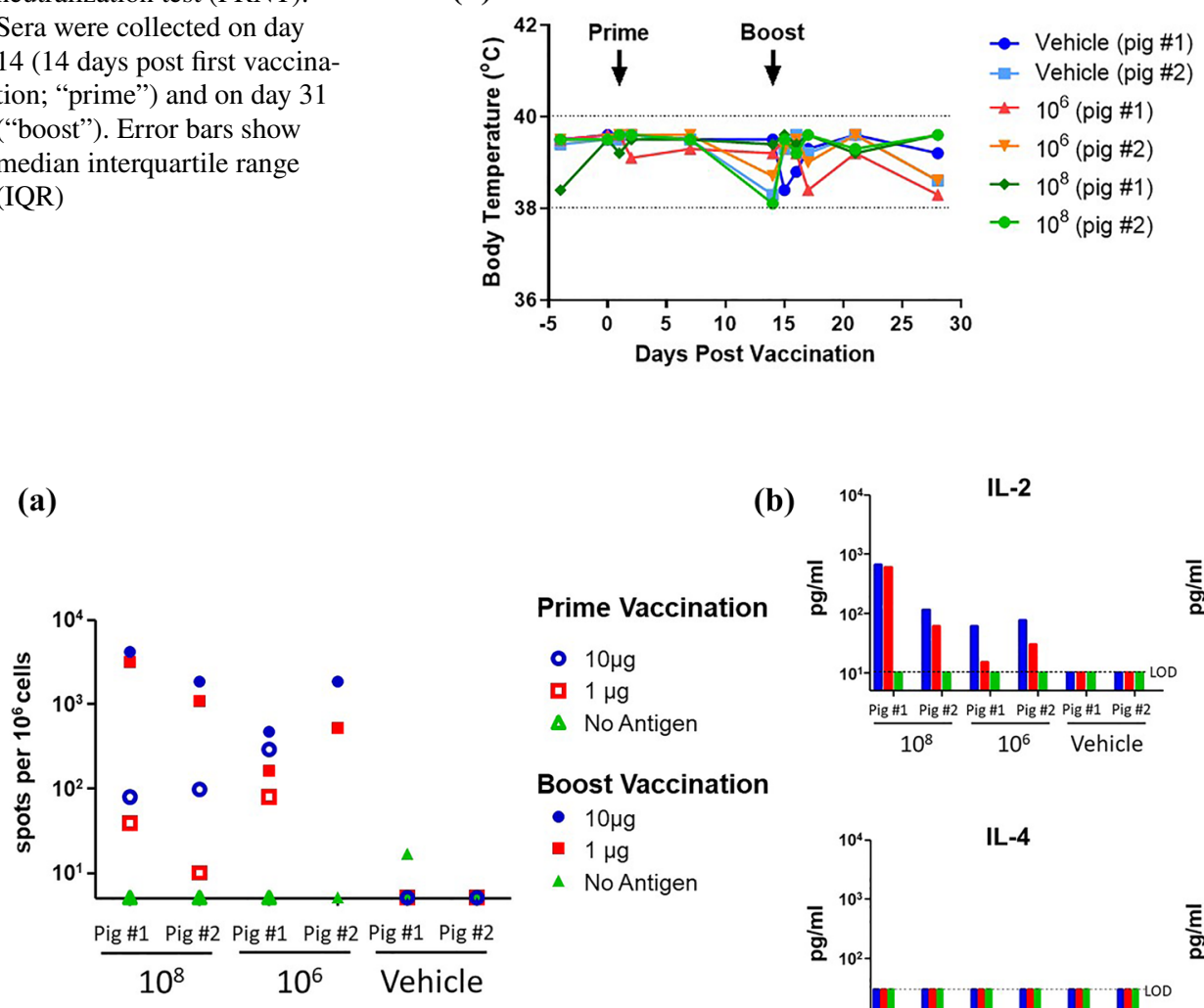

Fig. 4 Cytokine secretions in pigs after prime/boost vaccination. a IFN $\gamma$ secretion by Elispot assay: Antigen induced IFN $\gamma$ producing $\mathrm{T}$ cells (spots $/ 10^{6}$ PBMCs). b Cytokine secretion three weeks post boost dose in pigs: Cytokine measurements were in duplicates for no

rendered the viruses non-virulent and safe in general. In particular ERVEBO ${ }^{\circledR}$ was safe to the nervous system as demonstrated by intra-thalamic injection in non-human primates, compared to the highly neurovirulent wild-type VSV (VSV-WT) (Monath et al. 2019). To address the safety of rVSV- $\Delta$ G-SARS-CoV-2-S vaccine in the nervous system, a comparative neurovirulence study was conducted using a single intracranial (i.c.) injection at various doses of either the wild-type VSV (VSV-WT) or rVSV- $\Delta$ G-SARS-CoV-2-S vaccine to $\mathrm{C} 57 \mathrm{BL} / 6$ immune competent mice, and type I
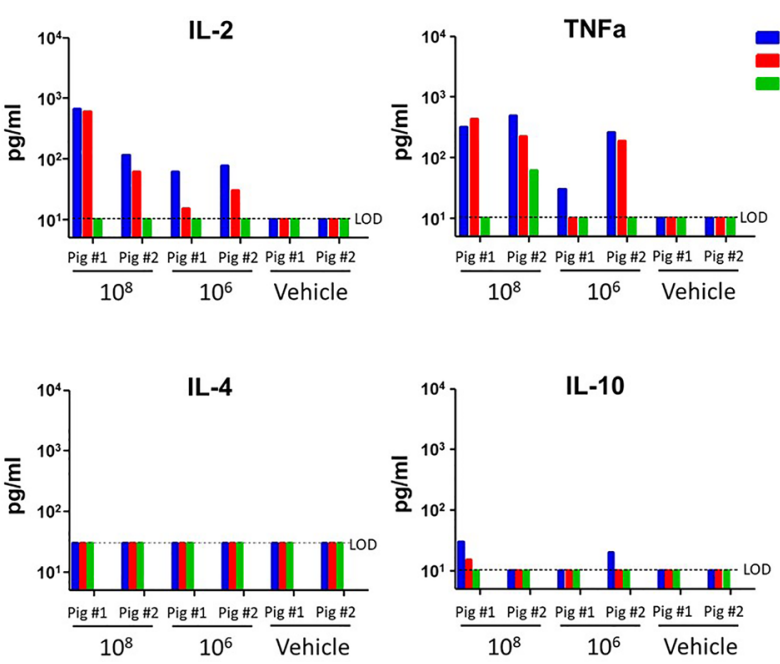

antigen controls and naïve animals, and were in quadruplates for pigs vaccinated with rVSV-SARS-CoV-2-S. Positive controls (not shown) were measured for each cytokine in duplicate

interferon receptor knock-out (IFNAR KO) mice. The latter are incapable of transducing signals through the interferon receptors alpha and beta and, as such, are highly sensitive to viral infections (Marin-Lopez et al. 2019).

In C57BL/6 immune competent mice, a single i.c. injection of VSV-WT at doses of $10^{3}, 10^{4}$ and $10^{5} \mathrm{PFU}$, resulted in rapid weight loss and death within $72 \mathrm{~h}$, while injection of a high dose of $10^{5} \mathrm{PFU}$ of rVSV- $\Delta$ G-SARS-CoV-2-S was well tolerated, with all mice surviving and no reduction observed in body weight $(n=3$ /group; Fig. 6a, Table 1$)$. In 


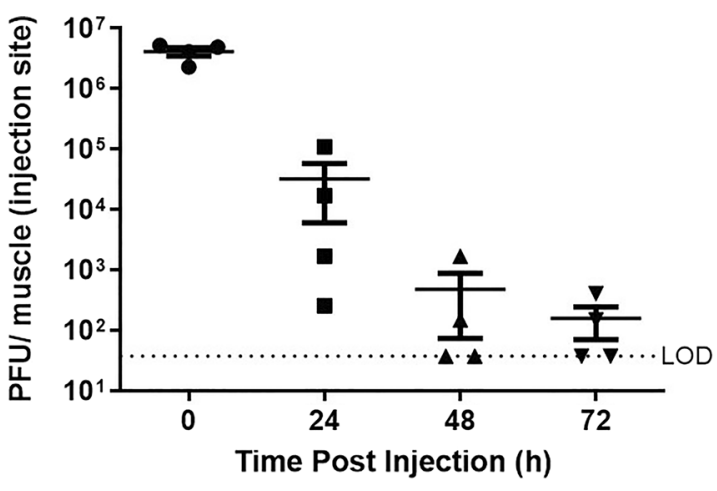

\begin{tabular}{|l|l|l|l|l|}
\hline $\begin{array}{l}\text { Time post } \\
\text { vaccination }\end{array}$ & $\begin{array}{l}\text { Average titer } \\
\text { (PFU/muscle) }\end{array}$ & SD & SEM & $\begin{array}{l}\text { \% relative } \\
\text { to time 0 }\end{array}$ \\
\hline $\mathbf{0 h}$ & $4.1 \mathrm{E}+06$ & $1.3 \mathrm{E}+06$ & $6.7 \mathrm{E}+05$ & 100.0 \\
\hline $\mathbf{2 4 h}$ & $3.2 \mathrm{E}+04$ & $5.2 \mathrm{E}+04$ & $2.6 \mathrm{E}+04$ & 0.8 \\
\hline $\mathbf{4 8 h}$ & $4.8 \mathrm{E}+02$ & $8.3 \mathrm{E}+02$ & $4.2 \mathrm{E}+02$ & 0.01 \\
\hline $\mathbf{7 2 h}$ & $1.4 \mathrm{E}+02$ & $1.9 \mathrm{E}+02$ & $9.7 \mathrm{E}+01$ & 0.003 \\
\hline
\end{tabular}

Fig. 5 Vaccine viral loads at the injection site in K18-hACE2 transgenic mice. Vaccine viral loads were determined at in the injection site (muscle) at the time points indicated following vaccine administration to K18-hACE2 transgenic mice

IFNAR KO mice, VSV-WT was uniformly lethal following a single i.c. injection at doses of $10^{2}$ or $10^{3} \mathrm{PFU} /$ mouse. Mice rapidly deteriorated and died within 48-72 $\mathrm{h}$. IFNAR KO mice injected i.c. with rVSV- $\Delta$ G-SARS-CoV-2-S vaccine at doses of $10^{3}$ or $10^{4} \mathrm{PFU} /$ mouse survived throughout the follow-up period. Mice did not show any sign of morbidity and no reduction in body weight was noted ( $n=3$ /group; Fig. 6b).

Histopathology evaluation of the brains of mice injected with rVSV- $\Delta$ G-SARS-CoV-2-S vaccine, from both strains, revealed no perivascular inflammatory infiltrate, no gliosis, no neurodegeneration, no satellitosis and no necrosis in all the evaluated brain areas (including the frontal cortex,

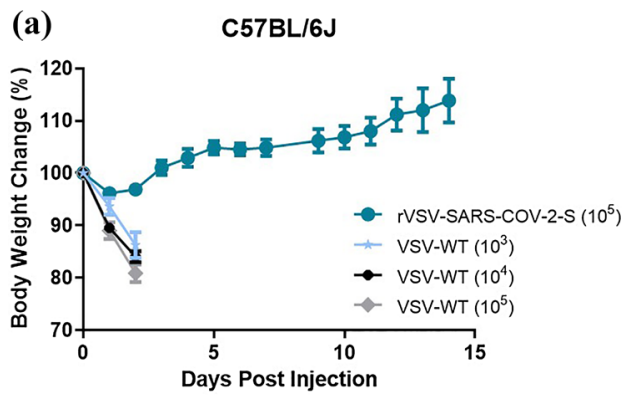

Fig. 6 Comparison of VSV-WT with rVSV- $\Delta$ G-SARS-CoV-2-S vaccine effects following i.c. administration to C57BL/6 J or IFNAR KO mice. a C57BL/6 J mice, 6-12 weeks of age, administered i.c. with VSV-WT or rVSV- $\Delta$ G-SARS-CoV-2-S vaccine virus at doses ranging from $10^{3}$ to $10^{5} \mathrm{PFU}$ ( $n=3 /$ group). b IFNAR KO mice, striatum, thalamus, hypothalamus, hippocampus and cerebellum); representative images from C57/BL6-injected mice are shown in Fig. 7. Neurovirulence was absent in both C57BL/6 immune competent mice and IFNAR KO mice, injected with the rVSV- $\Delta$ G-SARS-CoV-2-S vaccine.

In contrast, brains of mice injected with VSV-WT presented with profound histological damage. Pathology was pronounced in the striatum $(\mathrm{Sr})$ area, mainly in the Corpus Callosum (CC) and in the Medial Septal Nuclei sub regions (MSN), (Fig. S2), Thalamus (TH, mostly in lateral thalamus nuclei) and in the Hippocampus (Hc) (predominantly in the CC, Fig. S3). Damage consisted of extensive parenchymal inflammatory cells infiltration (lymphocytes, macrophages) in CC, MSN, TH brain regions and mild sporadic hemorrhages (detected only in $\mathrm{CC}$ area of the $\mathrm{Hc}$ ). These findings were accompanied by extensive necrosis and degeneration.

The apparent safety of the vaccine when inoculated directly into the brain of C57BL/ $6 \mathrm{~J}$ mice and, furthermore, to the sensitive IFNAR KO mice, confirms the safety of the vaccine with respect to the nervous system and strongly supports the overall safety profile of rVSV- $\Delta$ G-SARS-CoV-2-S vaccine.

\section{Discussion}

Beyond proving immunogenicity and efficacy, there is great importance to an in-depth characterization of the safety profile of a vaccine under development, in order to maintain public trust, especially in times of emergency. To this end, there is an advantage in choosing a vaccine platform which has already proven to be safe. In addition, the nonclinical safety profile should be carefully established in a variety of different models.

In light of the need for the development of vaccines for SARS-CoV-2 in a timely manner, we developed a replication competent recombinant VSV- $\Delta \mathrm{G}$-spike vaccine, in which

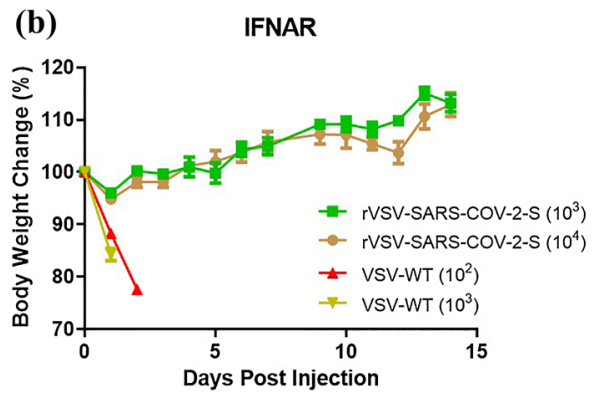

6-12 weeks of age, administered i.c. with VSV-WT or rVSV- $\Delta \mathrm{G}-$ SARS-CoV-2-S vaccine virus doses ranging from $10^{2}$ to $10^{4}$ PFU. VSV-WT-injected mice were censored at day $2 / 3$ due to lethality, while rVSV- $\Delta$ G-SARS-CoV-2-S-injected mice survived throughout the follow-up period (14 days) 
Fig. 7 Histopathology of C57/ BL6 mouse brain after injection with rVSV- $\Delta$ G-SARS-CoV-2-S. a Frontal cortex; b Striatum; c Thalamus; d Hypothalamus; e Hippocampus; f Cerebellum. Scale bar $=100 \mu \mathrm{m}$, Magnification: X10, H\&E staining
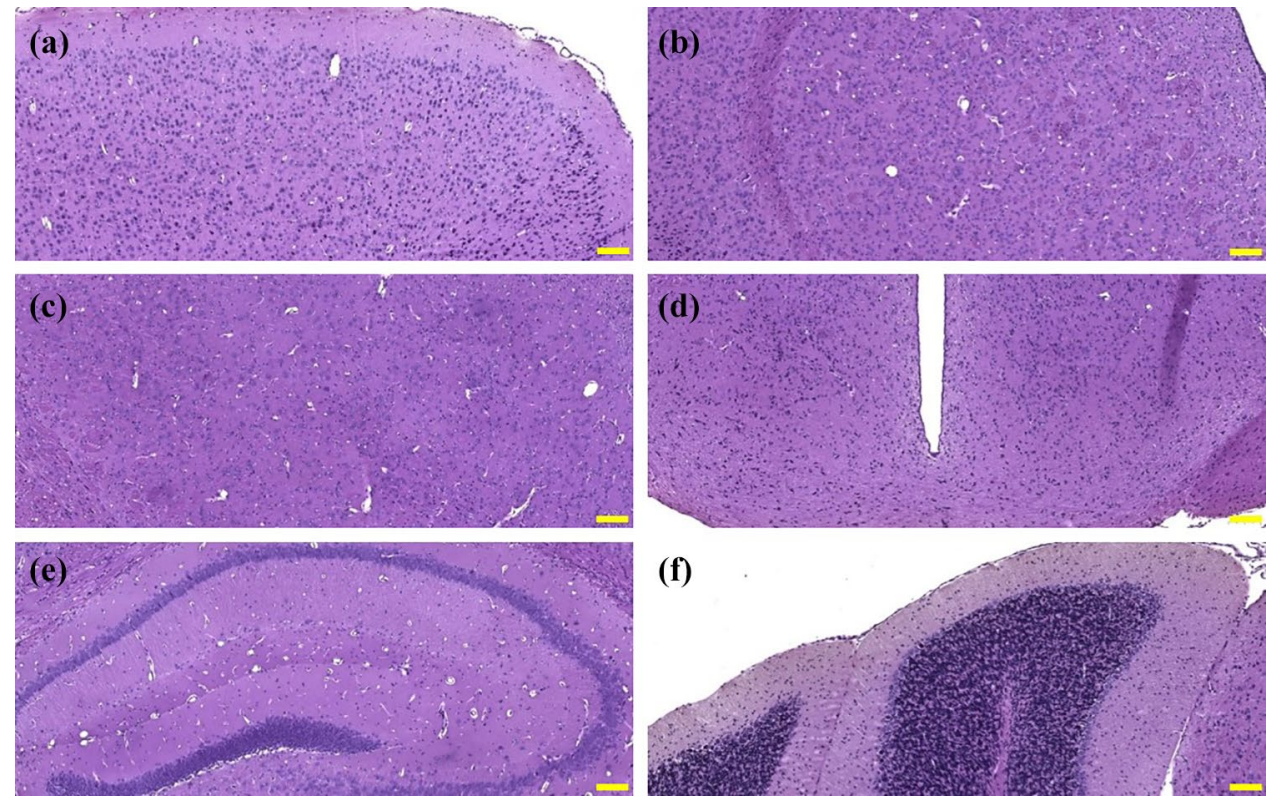

the $G$ gene which encodes the viral envelope glycoprotein of VSV was deleted from the viral genome and replaced with the S gene of SARS-CoV-2 (Yahalom-Ronen et al. 2020), which mediates entry to cells expressing hACE2 receptor and is a major viral surface antigen to which neutralizing antibodies and $\mathrm{T}$ cell response are induced. The rVSV- $\Delta$ G-SARS-CoV-2-S vaccine utilizes the VSV backbone employed by other live vaccines including rVSVEBOV which was approved by the FDA (under the trade name ERVEBO ${ }^{\circledR}$ ), at the end of 2019 , for the prevention of Zaire ebolavirus-caused disease in individuals 18 years of age and older (Available on line https://www.fda.gov/vacci nes-blood-biologics/ervebo). The proven efficacy of the ERVEBO $^{\circledR}$ vaccine to prevent Ebola infection in humans is remarkable and validates the VSV- $\Delta \mathrm{G}$ backbone as a platform to produce effective and safe vaccines (Fathi et al. 2019).

During the development and manufacturing processes, rVSV- $\Delta$ G-SARS-CoV-2-S vaccine evolution was accompanied by spontaneous acquisition of several mutations, some of which are at sites of major importance to antibodymediated immunity, such as N501 and E484 located in the receptor-binding domain (RBD) of the spike protein. Several additional mutations also emerged, such as R685G at the RRAR multi-basic SARS-CoV-2 furin cleavage site, located at the junction of the spike protein receptor-binding (S1) and fusion (S2) domains. Final vaccine batches are genetically stable. The ability of the candidate vaccine to confer protection against emerging SARS-CoV-2 variants of concern (VOCs) is currently being investigated.

To evaluate the safety profile of our rVSV- $\Delta$ G-SARS$\mathrm{CoV}-2-\mathrm{S}$ vaccine, we have completed a series of nonclinical safety, immunogenicity and efficacy (potency) studies in four animal species, mouse, hamster, rabbit and pig, using multiple dose levels, up to $10^{8} \mathrm{PFU} /$ animal (Table 1). In addition, a repeat-dose GLP toxicity study was conducted in rabbits (not described here). Justification for dose selection was based on available preclinical data (Yahalom-Ronen et al. 2020) and supported by relevant preclinical and clinical experience with the ERVEBO ${ }^{\circledR}$ vaccine.

Particular attention was given to species selection, which was based on scientific, ethical and practical factors. According to the WHO guidelines on nonclinical evaluation of vaccines, a relevant animal species should develop an immune response similar to the expected human response after vaccination. Ideally, the animal species should also be sensitive to the pathogenic organism, and/or mimic the disease in humans. In line with these recommendations, the tested species presented increased levels of binding and neutralizing antibodies in response to vaccination, supporting their relevancy. Since no single model is ideal, several complementary models were used.

The first model to be established, the golden Syrian hamster (Mesocricetus auratus) model, was found to be susceptible to the COVID-19 disease and was used for evaluation of both the safety and efficacy of the vaccine (Yahalom-Ronen et al. 2020). In addition, safety was evaluated in the K18 transgenic mouse model, which is considered a highly sensitive animal model for SARS-CoV-2. In these mice, human ACE-2-dependent replication of SARS and SARS-CoV-2 is observed, followed by morbidity and mortality (McCray et al. 2007; Munoz-Fontela et al. 2020).

Interestingly, accumulated data place the hamster and the transgenic mouse model as pivotal and indicative challenge models for SARS-CoV-2. While some other vaccine candidates have been tested in non-human primates (NHPs), 
the different NHP strains tested show a variable response to SARS-CoV-2 infection and thus, results may be difficult to interpret with respect to determining the effectiveness and safety of the vaccine tested (Munoz-Fontela et al. 2020). In addition, ethical considerations and limited availability of NHPs make this model less favorable and highly complex for use.

The rabbit, a non-rodent animal species, is considered suitably robust, sensitive and regulatory acceptable as an animal species for vaccine testing, and was shown to develop an antibody signature response to SARS-CoV-2 (Ravichandran et al. 2020). In addition, the observed histopathological changes in our vaccinated rabbits (i.e., increased lymphocytic cellularity in the germinal centers of the spleen and regional lymph node) were considered to reflect a secondary change, due to antigenic stimulation. Pigs, on the other hand, are more physiologically similar to humans than some other animal models, in terms of body weight and metabolic rate. The pig is a valuable model for testing human vaccines safety and immunogenicity (Gerdts et al. 2015). It may also provide an indication of the type of immune response induced and is thus considered a valid non-rodent model for nonclinical safety testing. In addition, the pig is considered to be an acceptable alternative to the dog, which is commonly used as non-rodent toxicology model, or to non-human primates which are less accessible and less easily justifiable for ethical reasons.

Altogether, the use of four different animal species, rodent and non-rodent, is important in building a reliable and comprehensive safety profile to support further clinical research.

Under the study conditions described here, the rVSV- $\Delta \mathrm{G}$ SARS-CoV-2-S vaccine was found to be well tolerated, did not raise any safety signals of concern, up to the highest dose tested $\left(10^{8} \mathrm{PFU}\right)$ and evoked high levels of neutralizing antibodies against SARS-CoV-2, in all species tested.

No shedding of the viral vaccine was detected in urine, nor was it found in blood. There were no rVSV- $\Delta$ G-SARS$\mathrm{CoV}-2-\mathrm{S}$-related histopathological changes in hamsters and pigs. In rabbits, the observed treatment-related histopathological findings (i.e., lymphoid hyperplasia in local lymph nodes and spleen, and mild local inflammation) are in line with what can be expected from an immunogenic vaccine with immune stimulation.

Interestingly, in a recent work by Sun et al., (2021), ACE-2 expression was profiled in cows, pigs, rabbits and goats. The authors have shown that in these animals, ACE-2 is highly expressed in multiple tissues but not in muscles. Therefore, it could be assumed that the observed immunogenicity in rabbits and pigs, following immunization with rVSV- $\Delta$ G-SARS-CoV-2-S is primarily driven by an antigen-based mechanism rather by active replication, which is further supported by the lack of viremia in these two animal models. In the K18 hACE2 transgenic mouse model, in which ACE-2 receptor is expressed under the K18 promoter demonstrated containment of the vaccine at the site of injection and its gradual clearance, with no distribution to the lungs. We also showed that viable vaccine virus remains up to $72 \mathrm{~h}$ post vaccination in some of the animals - a time window which supports the formation and induction of a robust immune response. It is important to note in this respect that in humans, hACE2 receptor is mostly expressed in the respiratory organs and the gastrointestinal tract. As the receptor distribution to the site of injection (muscle) is limited, vaccination with a VSV $\Delta \mathrm{G}$ spike-based vaccine is not expected to result in extensive replication, further supporting the vaccine's safety profile.

No evidence for neurovirulence was found following intracranial injection of the vaccine (a "worst possible case" scenario for maximal toxic effect) in C57BL/6 immune competent mice or in IFNAR KO mice, deficient in the interferon alpha/beta receptor, hence highly sensitive to viral infections, supporting our conclusion that upon removal of the VSV-G protein, the $\Delta \mathrm{G}$-based vaccine lost the inherent neurovirulence potential which is associated with the $\mathrm{G}$ protein, significantly contributing to its safety profile.

It is noteworthy that the emerging nonclinical safety profile of rVSV- $\Delta$ G-SARS-CoV-2-S vaccine is found to be very similar to that of the rVSV-EBOV (FDA Summary Basis For Regulatory Action Available on line https://www. fda.gov/media/134227/download; EMEA EPAR Available on line https://www.ema.europa.eu/en/medicines/human/ EPAR/ervebo). A single dose of rVSV-EBOV did not lead to any biologically significant rVSV-ZEBOV-GP-related effects on clinical observations, mortality, body weights, body temperature, clinical chemistry and hematology in the two animal models tested (mice and non-human primates). Similar treatment-related histopathological changes in injections site, iliac lymph nodes and spleen, observed here, also indicate a similar mechanism of vaccine-induced antigenic stimulation.

Novel vaccines necessarily require critical safety evaluation to address possible adverse effects, either antigenrelated (reactogenicity due to interaction with host pathways or immune related), or platform-related (over-replication, allergic or hyper-active immune response). Currently, several billion vaccine doses, exploiting the spike antigen, have been administered without major severe adverse events. As to the vaccine's platform, different platform technologies have their own pros and cons, but with increased use of a specific platform, the overall safety and efficacy profile becomes more established. This is the advantage of using the rVSV- $\Delta \mathrm{G}$ platform, an already approved platform (in terms of ERVEBO ${ }^{\circledR}$ ) to help establish the safety of our candidate vaccine. 
One major potential concern associated with COVID-19 vaccines is the risk of Vaccine-Associated Enhanced Disease (VAED), including, but not limited to Vaccine-Associated Enhanced Respiratory Disease (VAERD) which involves exacerbation of the respiratory viral infection's clinical presentation, via antibody and complement-mediated mechanisms (namely Antibody-Dependent Enhancement, ADE) or via antibody-independent mechanisms which may involve cytokine release or cellular immune activation, recently reviewed by Lee et al. (2020). As far as we know, to date, accumulating clinical data have shown no evidence of VAED/VAERD in any COVID-19 vaccine clinical trials, including those based on viral vectors. Nevertheless, VAED was previously noted in the development of Dengue virus, RSV (Graham 2016), and measles vaccines (Polack 2007). In addition, preclinical data with other coronaviruses family members, SARS-CoV and Middle East respiratory syndrome (MERS) (Du et al. 2016; Wang et al. 2014), also suggested signs of VAERD, when vaccinated animals were subsequently challenged with the wild-type SARS-CoV/MERS-CoV (Agrawal et al. 2016; Weingartl et al. 2004), and developed immuno-pathologic lung reactions that were attributed to a Th-2-biased immune response.

According to the recent FDA guidance document for development and licensure of COVID-19 vaccines (Available on line https://www.fda.gov/regulatory-information/ search-fda-guidance-documents/development-and-licen sure-vaccines-prevent-covid-19), assessment of potential enhanced respiratory disease (ERD) in preclinical models should include an evaluation of neutralization versus total antibody responses, and a Th1/Th2 balance. A vaccine showing a relatively high antibody titer of neutralizing antibodies, and an immune response that is primarily $\mathrm{Th} 1$, is thereby considered at low risk for ERD. Accordingly, vaccination with rVSV- $\Delta$ G-SARS-CoV-2-S vaccine led to high neutralizing antibody titers in all animal species tested, and a Th1-type T cell polarization was demonstrated in pigs, manifested by IFN $\gamma$, IL-2 and TNF $\alpha$ production but not Th2 cytokines (IL-4, IL-10) in spike-stimulated PBMCs. These results are consistent with what is generally known for other vaccines based on live viruses, specifically, for the VSV- $\Delta \mathrm{G}$ platform which was shown to elicit such a response (Farooq et al. 2016). Furthermore, using two reliable SARS-CoV-2 challenge models, Syrian hamsters (Yahalom-Ronen et al. 2020) and K18 hACE2 transgenic mice (data not shown), we demonstrated that vaccination with rVSV- $\Delta$ G-SARSCoV-2-S vaccine protected the animals, and did not lead to disease enhancement, once the animals were subjected to a challenge with the wild-type SARS-CoV-2 virus. Lungs of these animals were sustainably less damaged, and exhibited reduced viral load and improved in tissue-to-air ratio, as compared to infected, unvaccinated animals.

\section{Conclusion}

In conclusion, $r V S V-\Delta$ G-SARS-CoV-2-S vaccine was found to be safe and immunogenic in a series of nonclinical studies, conducted in four animal species (rodent and non-rodent), using multiple doses (up to $10^{8} \mathrm{PFU} / \mathrm{animal}$ ) and various dosing regimens. There were no treatmentrelated mortalities in any study, nor any noticeable systemic or local clinical signs. The rVSV- $\Delta$ G-SARS-CoV$2-S$ vaccine immune response gave rise to neutralizing antibodies, cellular immune response, and increased lymphocytic cellularity in the spleen germinal centers and regional lymph node. These studies were part of the nonclinical package that supported the initiation of clinical trials (NCT04608305), currently in Phase 2.

Supplementary Information The online version contains supplementary material available at https://doi.org/10.1007/s00204-021-03214-w.

Acknowledgements We acknowledge the IIBR administrative personnel for their commitment to the project. We thank Yossi Shlomovich, Noa Caspi and Ruchama Brody from IIBR animal husbandry; Yossi Lavie, Tal Levin-Harrus, Shkedia Kohen, Raphael Lioz and Boaz Nachshon from Envigo CRS (Israel) Ltd., Ness Ziona, Israel; Dr. Emmanuel Loeb from Patho-Logica Ltd; Dr. Tami Horovitz from Gsap, Israel for scientific editing of the manuscript; Prof. Eran Bacharach (Tel Aviv University) who kindly provided VSV-Indiana (WT-VSV) and the Bundeswehr Institute of Microbiology, Munich, Germany that kindly provided SARS-CoV-2 (GISAID accession EPI_ISL_406862).

Author contributions Conceived of or designed study: NMB, SM, BP, MS, HT, YYR, EBH, SY, ABD, HL, NP, TI, HM; Performed research: AR, SM, BP, HT, YYR, EBD, ABS, AS, IG, SW, EBH, HC, UE, HA, NE, SR, SL, AN, ABD, HL, NP, TI; Contributed new methods or models: NMB, AR, SM, BP, MS, HT, YYR, EBH, HC, UE, SR, SL, AN, ABD, HL, NP, TI; Wrote the paper: NMB, AR, SM, BP, MS, HT, YYR, EBD, ABS, AS, IG, SW, EBH, HC, UE, HA, NE, SR, SL, AN, SY, ABD, HL, NP, TI, HM. All authors have read and agreed to the published version of the manuscript.

Funding This research received no external funding.

\section{Declarations}

Conflict of interest The authors declare that they have no conflict of interest.

Ethical approval Experiments were approved by the IIBR animal care and use committee (IACUC) and performed in accordance with the guidelines of the care and use of laboratory animals published by the Israeli Ministry of Health (protocols: mice C57BL/6J \# No. M-52-20, Ifnar1 knock-out and hACE2-K18 mice \# No. M-65-20, hamster \# No. HM-02-20, rabbits \# No. RB-13-29, pigs \# No. P-03-20).

Patents Patent application for the described vaccine was filed by the Israel Institute for Biological Research. 


\section{References}

Agrawal AS, Tao X, Algaissi A et al (2016) Immunization with inactivated Middle East Respiratory Syndrome coronavirus vaccine leads to lung immunopathology on challenge with live virus. Hum Vaccin Immunother 12(9):2351-2356. https://doi.org/10. 1080/21645515.2016.1177688

Baldrick P (2016) Dose site reactions and related findings after vaccine administration in safety studies. J Appl Toxicol 36(8):980 990. https://doi.org/10.1002/jat.3314

Corman VM, Landt O, Kaiser M et al (2020) Detection of 2019 novel coronavirus (2019-nCoV) by real-time RT-PCR. Euro Surveill. https://doi.org/10.2807/1560-7917.ES.2020.25.3.2000045

Du L, Tai W, Zhou Y, Jiang S (2016) Vaccines for the prevention against the threat of MERS-CoV. Expert Rev Vaccines 15(9):1123-1134. https://doi.org/10.1586/14760584.2016. 1167603

Farooq F, Beck K, Paolino KM et al (2016) Circulating follicular T helper cells and cytokine profile in humans following vaccination with the rVSV-ZEBOV Ebola vaccine. Sci Rep 6:27944. https://doi.org/10.1038/srep27944

Fathi A, Dahlke C, Addo MM (2019) Recombinant vesicular stomatitis virus vector vaccines for WHO blueprint priority pathogens. Hum Vaccin Immunother 15(10):2269-2285. https://doi.org/10. $1080 / 21645515.2019 .1649532$

Gerdts V, Wilson HL, Meurens F et al (2015) Large animal models for vaccine development and testing. ILAR J 56(1):53-62. https://doi.org/10.1093/ilar/ilv009

Golden JW, Zeng X, Cline CR et al (2021) Human convalescent plasma protects K18-hACE2 mice against severe respiratory disease. J Gen Virol. https://doi.org/10.1099/jgv.0.001599

Graham BS (2016) Vaccines against respiratory syncytial virus: the time has finally come. Vaccine 34(30):3535-3541. https://doi. org/10.1016/j.vaccine.2016.04.083

Grieves JL, Dick EJ Jr, Schlabritz-Loutsevich NE et al (2008) Barbiturate euthanasia solution-induced tissue artifact in nonhuman primates. J Med Primatol 37(3):154-161. https://doi.org/10. 1111/j.1600-0684.2007.00271.x

Hannon JP, Bossone CA, Wade CE (1990) Normal physiological values for conscious pigs used in biomedical research. Lab Anim Sci 40(3):293-298

Israely T, Paran N, Erez N et al (2019) Differential Response Following Infection of Mouse CNS with Virulent and Attenuated Vaccinia Virus Strains. Vaccines (basel). https://doi.org/10. 3390/vaccines7010019

Israely T, Paran N, Lustig S et al (2012) A single cidofovir treatment rescues animals at progressive stages of lethal orthopoxvirus disease. Virol J 9:119. https://doi.org/10.1186/1743-422X-9-119

Lawson ND, Stillman EA, Whitt MA, Rose JK (1995) Recombinant vesicular stomatitis viruses from DNA. Proc Natl Acad Sci U S A 92(10):4477-4481. https://doi.org/10.1073/pnas.92.10.4477

Lee WS, Wheatley AK, Kent SJ, DeKosky BJ (2020) Antibodydependent enhancement and SARS-CoV-2 vaccines and therapies. Nat Microbiol 5(10):1185-1191. https://doi.org/10.1038/ s41564-020-00789-5

Marin-Lopez A, Calvo-Pinilla E, Moreno S et al (2019) Modeling arboviral infection in mice lacking the interferon alpha/beta receptor. Viruses. https://doi.org/10.3390/v11010035

McCray PB Jr, Pewe L, Wohlford-Lenane C et al (2007) Lethal infection of K18-hACE2 mice infected with severe acute respiratory syndrome coronavirus. J Virol 81(2):813-821. https://doi.org/ 10.1128/JVI.02012-06

Mire CE, Miller AD, Carville A et al (2012) Recombinant vesicular stomatitis virus vaccine vectors expressing filovirus glycoproteins lack neurovirulence in nonhuman primates. PLoS Negl
Trop Dis 6(3):e1567. https://doi.org/10.1371/journal.pntd. 0001567

Monath TP, Fast PE, Modjarrad K et al (2019) rVSVDeltaG-ZEBOVGP (also designated V920) recombinant vesicular stomatitis virus pseudotyped with Ebola Zaire Glycoprotein: Standardized template with key considerations for a risk/benefit assessment. Vaccine X 1:100009. https://doi.org/10.1016/j.jvacx.2019.100009

Muik A, Kneiske I, Werbizki M et al (2011) Pseudotyping vesicular stomatitis virus with lymphocytic choriomeningitis virus glycoproteins enhances infectivity for glioma cells and minimizes neurotropism. J Virol 85(11):5679-5684. https://doi.org/10.1128/ JVI.02511-10

Muik A, Stubbert LJ, Jahedi RZ et al (2014) Re-engineering vesicular stomatitis virus to abrogate neurotoxicity, circumvent humoral immunity, and enhance oncolytic potency. Cancer Res 74(13):3567-3578. https://doi.org/10.1158/0008-5472. CAN-13-3306

Munoz-Fontela C, Dowling WE, Funnell SGP et al (2020) Animal models for COVID-19. Nature 586(7830):509-515. https://doi. org/10.1038/s41586-020-2787-6

Noy-Porat T, Makdasi E, Alcalay R et al (2020) A panel of human neutralizing mAbs targeting SARS-CoV-2 spike at multiple epitopes. Nat Commun 11(1):4303. https://doi.org/10.1038/ s41467-020-18159-4

Polack FP (2007) Atypical measles and enhanced respiratory syncytial virus disease (ERD) made simple. Pediatr Res 62(1):111-115. https://doi.org/10.1203/PDR.0b013e3180686ce0

Ravichandran S, Coyle EM, Klenow L et al (2020) Antibody signature induced by SARS-CoV-2 spike protein immunogens in rabbits. Sci Transl Med. https://doi.org/10.1126/scitranslmed.abc3539

Rodriguez-Guerra M, Jadhav P, Vittorio TJ (2021) Current treatment in COVID-19 disease: a rapid review. Drugs Context. https://doi. org/10.7573/dic.2020-10-3

Schafer KA, Eighmy J, Fikes JD et al (2018) Use of severity grades to characterize histopathologic changes. Toxicol Pathol 46(3):256265. https://doi.org/10.1177/0192623318761348

Suder E, Furuyama W, Feldmann H, Marzi A, de Wit E (2018) The vesicular stomatitis virus-based Ebola virus vaccine: from concept to clinical trials. Hum Vaccin Immunother 14(9):2107-2113. https://doi.org/10.1080/21645515.2018.1473698

Sun K, Gu L, Ma L et al (2021) Atlas of ACE2 gene expression reveals novel insights into transmission of SARS-CoV-2. Heliyon 7(1):e05850. https://doi.org/10.1016/j.heliyon.2020.e05850

Wang SF, Tseng SP, Yen CH et al (2014) Antibody-dependent SARS coronavirus infection is mediated by antibodies against spike proteins. Biochem Biophys Res Commun 451(2):208-214. https:// doi.org/10.1016/j.bbrc.2014.07.090

Weingartl H, Czub M, Czub S et al (2004) Immunization with modified vaccinia virus Ankara-based recombinant vaccine against severe acute respiratory syndrome is associated with enhanced hepatitis in ferrets. J Virol 78(22):12672-12676. https://doi.org/10.1128/ JVI.78.22.12672-12676.2004

Welte T, Ambrose LJ, Sibbring GC, Sheikh S, Mullerova H, Sabir I (2021) Current evidence for COVID-19 therapies: a systematic literature review. Eur Respir Rev. https://doi.org/10.1183/16000 617.0384-2020

Willard-Mack CL, Elmore SA, Hall WC et al (2019) Nonproliferative and proliferative lesions of the rat and mouse hematolymphoid system. Toxicol Pathol 47(6):665-783. https://doi.org/10.1177/ 0192623319867053

Yahalom-Ronen Y, Tamir H, Melamed S et al (2020) A single dose of recombinant VSV-G-spike vaccine provides protection against SARS-CoV-2 challenge. Nat Commun 11(1):6402. https://doi.org/ 10.1038/s41467-020-20228-7

Yinda CK, Port JR, Bushmaker T et al (2021) K18-hACE2 mice develop respiratory disease resembling severe COVID-19. PLoS 
Pathog 17(1):e1009195. https://doi.org/10.1371/journal.ppat. 1009195

Zheng J, Wong LR, Li K et al (2021) COVID-19 treatments and pathogenesis including anosmia in K18-hACE2 mice. Nature 589(7843):603-607. https://doi.org/10.1038/s41586-020-2943-Z
Publisher's Note Springer Nature remains neutral with regard to jurisdictional claims in published maps and institutional affiliations. 